\title{
Mechanical Properties, Failure Mode, and Microstructure of Soil-Cement Modified with Fly Ash and Polypropylene Fiber
}

\author{
Xue-lei Duan (iD ${ }^{1,2}$ and Jing-shuang Zhang iD $^{1,2}$ \\ ${ }^{1}$ Engineering Research Center of Underground Mine Construction, Ministry of Education, \\ Anhui University of Science and Technology, Huainan 232001, Anhui, China \\ ${ }^{2}$ School of Civil Engineering and Architecture, Anhui University of Science and Technology, Huainan 232001, Anhui, China
}

Correspondence should be addressed to Jing-shuang Zhang; hnaust@163.com

Received 27 February 2019; Revised 3 April 2019; Accepted 16 April 2019; Published 6 May 2019

Guest Editor: Alena Šišková

Copyright ( $) 2019$ Xue-lei Duan and Jing-shuang Zhang. This is an open access article distributed under the Creative Commons Attribution License, which permits unrestricted use, distribution, and reproduction in any medium, provided the original work is properly cited.

\begin{abstract}
In order to investigate the effects of fly ash and polypropylene fiber on mechanical properties, failure mode, and microstructure of soil-cement, the unconfined compression test, splitting tension test, and scanning electron microscopy (SEM) test of soil-cement with different polypropylene fiber contents $(0 \%, 0.1 \%, 0.2 \%, 0.3 \%, 0.4 \%$, and $0.5 \%$ by weight of dry soil) and fly ash contents $(0 \%$, $4 \%, 8 \%$, and $12 \%$ by weight of dry soil) were carried out. The compressive and tensile strengths, deformation characteristics, failure mode, and microstructure of soil-cement modified with fly ash and polypropylene fiber were analyzed. The results show that the unconfined compressive strength and splitting tensile strength of soil-cement show a trend of increasing first and then decreasing with the increase of polypropylene fiber and fly ash content. Under the condition of $0.4 \%$ polypropylene fiber and $8 \%$ fly ash, the unconfined compressive strength and the splitting tensile strength are $4.90 \mathrm{MPa}$ and $0.91 \mathrm{MPa}$, respectively, which increased by $32.79 \%$ and $51.67 \%$ as compared with the plain soil-cement, respectively. When $8 \%$ fly ash was used in the experiment, the unconfined compressive peak strain and the splitting tensile peak strain of the inclusion of $0.4 \%$ polypropylene fiber were 0.0410 and 0.0196 , respectively. The corresponding peak strains were increased by $20.94 \%$ and $68.97 \%$ as compared with non-fiberstabilized soil-cement, respectively. The stress-strain curve of fly ash soil-cement modified with polypropylene fiber can be divided into compaction phase, linear rise phase, nonlinear rise phase, and failure phase. Polypropylene fiber constrains the lateral deformation of fly ash soil-cement, which improves the peak strain and the failure mode of soil-cement.
\end{abstract}

\section{Introduction}

Soil-cement is a kind of composite material composed of cement, soil, and other components. Due to the rapid development of global economy, as an environmentally friendly material, soil-cement has been widely used in soft soil foundation reinforcement, slope support, and channel lining in construction projects (roads, bridges, ports, etc.) [1-4]. Soil-cement has the advantages of easy access to draw materials, low price, and convenient construction. However, soil-cement material tends to have lower mechanical properties (e.g., unconfined compressive strength, shear strength, and triaxial compressive strength) and greater deformation in engineering projects [5-7], which might lead to the damage of building structures.
In order to lenify the disease in engineering projects, stabilization method that is a technique to treat soil-cement has been widely applied in infrastructure construction. Researchers tried to add chemical additives (fly ash, lime, and silicon powder) in soil-cement for improving its mechanical properties [8-10]. As one kind of stabilizers, fly ash that is the main solid waste discharged from coal-fired power plants has been widely employed to increase its strength. Yang et al. [11] studied the incorporation of cement and fly ash for improving the strength of cement-stirred saturated loess and pointed out that the suitable ratio between fly ash and cement was 0.5 , which was more economical and reasonable. Jia et al. [12] utilized cement and fly ash to strengthen soft clay and found that the inclusion of $6 \%$ fly ash and $16 \%$ cement could excellently improve its 
compressive strength. According to statistics, fly ash has reached 620 million tons in 2015, and every 10,000 tons of fly ash occupy four to five acres of land [13], which not only occupies a large amount of land resources but also causes serious environmental pollution. Therefore, the use of fly ash is getting more and more attention. Adding fly ash to soilcement could solve the problems of land occupation and environmental pollution.

Fiber-reinforced soil has attracted the attention of modern researchers, which makes contribution to not only the reduction in the amount of used cement but also the improvement of strength and deformation [14-20]. Chen [16] investigated the effect of basalt fiber on the tensile strength of soil-cement and revealed that the inclusion of $1.5 \%$ basalt fiber could attain a maximum tensile strength. Zhang et al. [17] added the asbestos fiber into fly ash soilcement and obtained that the strength of $6 \%$ asbestos fiberreinforced fly ash soil-cement increased by $140 \%$ as compared with fiber unreinforced fly ash soil-cement. Tran et al. [18] studied the toughness of waste cornsilk fiber in soil-cement and found that $0.25 \%-0.5 \%$ fibers were recommended to use in soil-cement. Due to the degradation of natural fiber in soil, synthetic fibers (e.g., glass fiber, nylon fiber, and polypropylene fiber) are employed as the inclusion [21-25]. Li et al. [21] added the glass fiber into the soil-cement and found that under the condition of $0.6 \%$ glass fiber, the soil particles and mineral particles can be in maximum contact with the fiber, showing the excellent mechanical performance. Park [22] studied the effect of the polyvinyl alcohol fiber on cemented sand and found that $2 \%$ polyvinyl alcohol fiber could improve the compressive strength of 2.5 times as compared with non-fiber-stabilized cemented soil. In these fibers, polypropylene fiber that can enhance the soil strength and reduce the shrinkage is widely used. Tang and $\mathrm{Gu}$ [23] studied the addition of polypropylene fiber in soil-cement to reduce the brittleness of soil-cement and revealed that bond strength and friction at the interface seem to be the dominant mechanism controlling the reinforcement benefit. Consoli et al. [24] investigated that the inclusion of polypropylene fiber in the soil-cement increased the unconfined compressive strength and proposed a porosity/volumetric cement content for predicting the unconfined compressive strength. Some scholars had also studied the effects of mixing different fibers on the strength and deformation of soil-cement $[26,27]$. Zhang et al. [26] analyzed that the unconfined compressive strength of both sisal fiber and polypropylene fiber into soil-cement could increase by $40.5 \%-54.1 \%$ as compared with plain soil-cement. Gutiérrez-Orrego et al. [27] found that soil-cement blocks reinforced with mineral wool and sisal fiber increased both bending strength and compression strength. The previous investigations primarily concentrated on macroscopic mechanical properties of soil-cement, and limited studies are available on microstructure analysis of stabilized soil-cement. The experiment of microstructure reflects the internal structure mechanism [28, 29].

The primary objective of this paper is to explore the effects of polypropylene fiber and fly ash content on unconfined compressive strength, splitting tensile strength, deformation characteristics, failure mode, and microstructure of soil-cement. To achieve this purpose, a series of unconfined compression test, splitting tension test, and SEM test were carried out.

\section{Experiment Materials and Sample Preparation}

2.1. Materials. The soil employed in the experiment was taken from the foundation pit of a construction site, located in east region of China in Huainan city. The depth of the soil was from the underground of $5 \mathrm{~m}$. The physical properties of soil are listed in Table 1. The fly ash used in this research was grade II and its chemical composition is listed in Table 2. In addition, particle size distribution of clayey soil and fly ash is shown in Figure 1. The cement used in the study was P.O 42.5 ordinary Portland cement, which was produced by Huainan Cement Corporation. The polypropylene fiber (Figure 2) was chosen as reinforcement material due to its high tensile strength, low cost, easy to mix with soil, and nonpolluting property for environment. The main physical and mechanical parameters are shown in Table 3. The water for mixing was tap water.

2.2. Sample Preparation. In the experiment, cement content was incorporated $15 \%$ by weight of dry soil and between water and cementitious materials was 0.5 . Additionally, in order to investigate the effects of fly ash and polypropylene fiber content on strength properties (unconfined compressive strength and splitting tensile strength) and failure mode of the soil-cement, four percentages of fly ash contents $(0 \%, 4 \%, 8 \%$, and $12 \%$ by weight of dry soil) and six percentages of polypropylene fiber contents $(0 \%, 0.1 \%, 0.2 \%$, $0.3 \%, 0.4 \%$, and $0.5 \%$ by weight of dry soil) were adopted in this study. In order to activate the active ingredient of the fly ash, calcium hydroxide ( $1 \%$ by weight of soil-cement) with a purity of more than $95 \%$ was employed [30].

In accordance with the standard for soil test method (GB/T 50123-1999), the test procedure was as follows. (1) The soil was dried, crushed, and passed through a $2 \mathrm{~mm}$ sieve. (2) Water was added to the dry soil to natural moisture content, which was made of soil sample. Then, sealed soil sample settled for at least 24 hours to ensure uniform moisture distribution. (3) After this time, according to the design to weigh various materials, cement was added to the soil sample and mixed well, which was made of soil-cement sample. (4) Fly ash, calcium hydroxide, and polypropylene fiber were added to soil-cement sample in sequence. (5) The prepared samples were divided into three parts for placement in the molds. Every layer interface was roughed up to ensure good surface-to-surface contact, which made it possible to more accurately manufacture soil-cement samples. In this experiment, the unconfined compressive strength samples were prepared with the cube of $70.7 \mathrm{~mm}$, and splitting tensile strength samples were prepared with a diameter of $50 \mathrm{~mm}$ and a height of $50 \mathrm{~mm}$. To prevent moisture loss, the samples were sealed with plastic film for at 
TABLE 1: Physical properties of clay.

\begin{tabular}{lc}
\hline Parameter & Value \\
\hline Natural moisture content (\%) & 23.80 \\
Severe $\left(\mathrm{kN} / \mathrm{m}^{3}\right)$ & 19.20 \\
Pore ratio & 0.74 \\
Liquid limit (\%) & 41.60 \\
Plastic limit (\%) & 22.00 \\
Plasticity index & 19.60 \\
\hline
\end{tabular}

TABLE 2: Chemical composition of fly ash.

\begin{tabular}{lc}
\hline Compound & Percent by weight \\
\hline $\mathrm{SiO}_{2}$ & 54.18 \\
$\mathrm{Al}_{2} \mathrm{O}_{3}$ & 22.35 \\
$\mathrm{Fe}_{2} \mathrm{O}_{3}$ & 12.36 \\
$\mathrm{CaO}$ & 0.40 \\
$\mathrm{MgO}$ & 0.06 \\
$\mathrm{~K}_{2} \mathrm{O}$ & 3.88 \\
$\mathrm{Na}_{2} \mathrm{O}$ & 2.62 \\
$\mathrm{TiO}_{2}$ & 4.13 \\
Other oxides & 0.02 \\
\hline
\end{tabular}

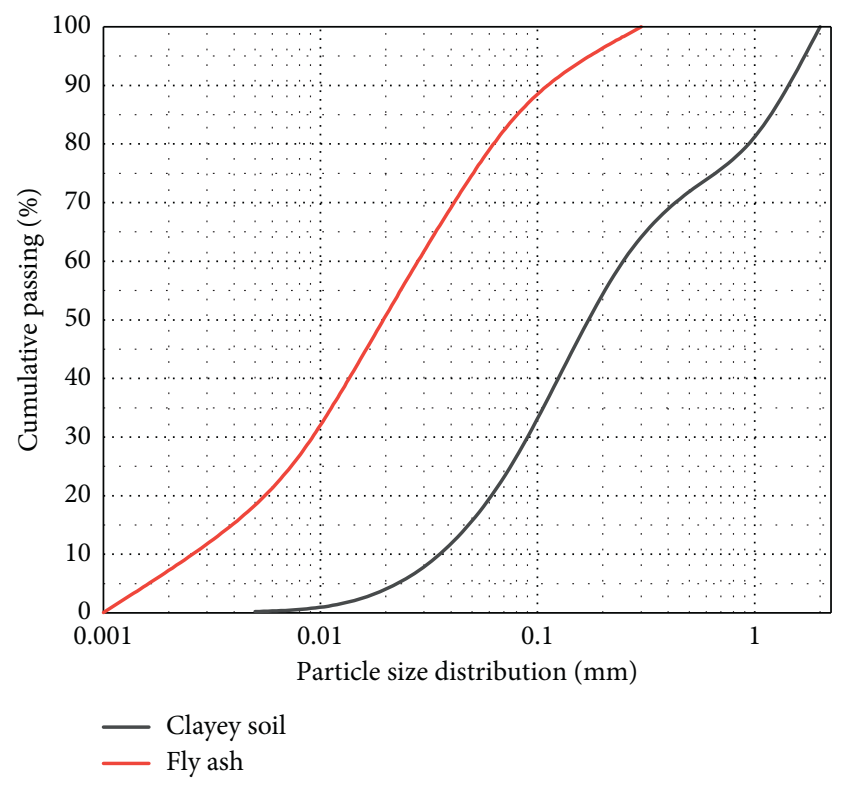

Figure 1: Particle size distribution of clayey soil and fly ash.

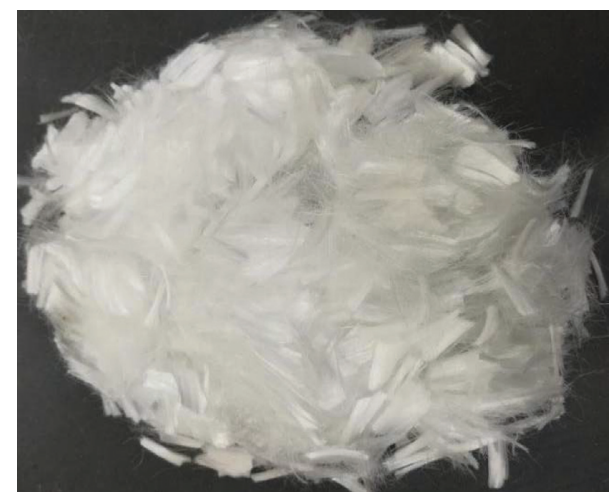

Figure 2: Photograph of polypropylene fibers.
TABle 3: Physical properties of polypropylene fibers.

\begin{tabular}{lc}
\hline Parameter & Value \\
\hline Fiber type & Single fiber \\
Density $\left(\mathrm{g} \cdot \mathrm{cm}^{-3}\right)$ & 0.91 \\
Length $(\mathrm{mm})$ & 12.00 \\
Diameter $(\mu \mathrm{m})$ & 48.00 \\
Elongation at break $(\%)$ & 15.00 \\
Modulus of elasticity $(\mathrm{GPa})$ & 4.80 \\
Breaking tensile strength $(\mathrm{MPa})$ & 486.00
\end{tabular}

least $24 \mathrm{~h}$, and then the demoulded samples were placed into sealed plastic bag. According to the standard of curing method stabilized soil (JTG E51-2009) [31], samples were placed into a standard moisture room with temperature maintained at $(20 \pm 2)^{\circ} \mathrm{C}$ and relative moisture above $95 \%$ for curing. The curing duration was determined to be twentyeight days.

There are 24 groups of samples in the research, and three sets of parallel specimens for the unconfined compressive strength and splitting tensile strength were prepared to control the accuracy of the result. For abbreviating, the samples are numbered by some symbols, and the meaning of abbreviations is explained later. The samples FA8-PP0.4 were on behalf of the sample which has $8 \%$ fly ash content and $0.4 \%$ polypropylene fiber content. WDW-20 microcomputer-controlled electronic universal testing machine with a maximum load sense of $100 \mathrm{kN}$ was employed to conduct the unconfined compression test and splitting tension test. Loading was applied on the sample at a constant displacement rate of $1 \mathrm{~mm}$ per minute and continued until sample failure. The microscopic experiment of soil-cement blocks were investigated through scanning electron microscopy (SEM) method, which observed the internal changes in the microstructure. The SEM observations were conducted on blocks taken from a cylindrical sample with a height of $50 \mathrm{~mm}$ and a diameter of $50 \mathrm{~mm}$. The blocks removed from soil-cement sample were immersed in ethanol for half an hour and then placed in an oven for drying. In addition, the SEM samples were gold coated by a sputtering technique to make them conductive after drying process. The SEM examinations were performed by using Hitachi S-3400N scanning electron microscope. Figure 3 shows preparation of soil-cement for unconfined compression test, splitting tension test, and SEM test.

\section{Experimental Results}

3.1. Unconfined Compression Test. Effect of fly ash content on unconfined compressive strength of soil-cement is presented in Figure 4. In order to better describe the influence of polypropylene fiber and fly ash content on the unconfined compressive strength, the strength growth rate $\eta$ is defined:

$$
\eta=\frac{\sigma_{\mathrm{n}}-\sigma_{0}}{\sigma_{0}} \times 100 \%,
$$

where $\sigma_{\mathrm{n}}$ is the unconfined compressive strength of soilcement with different polypropylene fiber and fly ash 


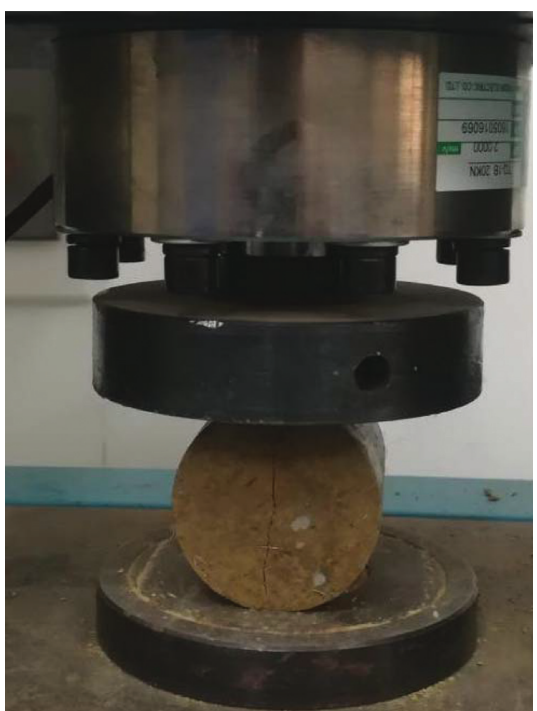

(a)

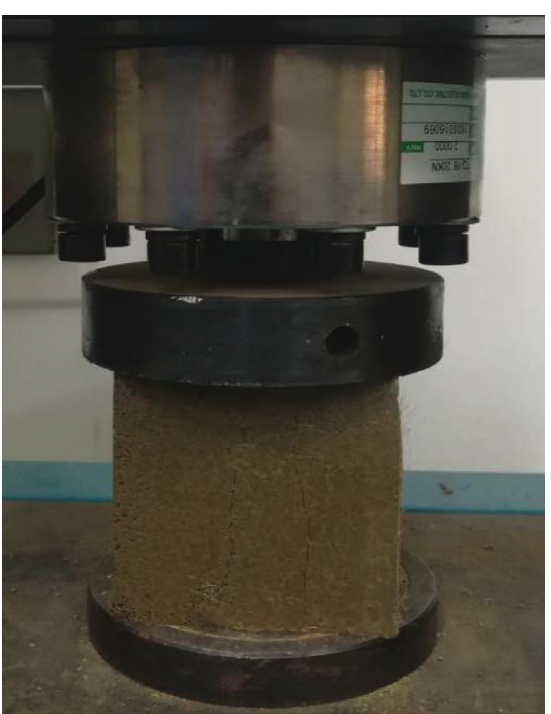

(b)
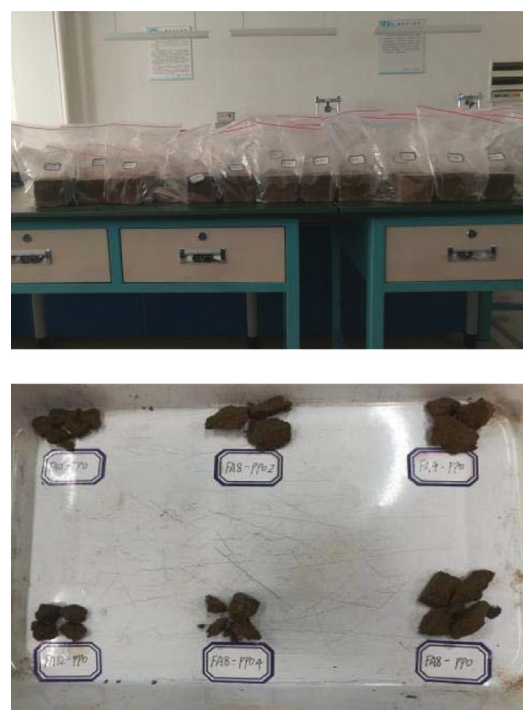

(c)

Figure 3: Preparation of soil-cement for unconfined compression test, splitting tension test, and SEM test. (a) Splitting tension test. (b) Unconfined compression test. (c) The prepared samples.

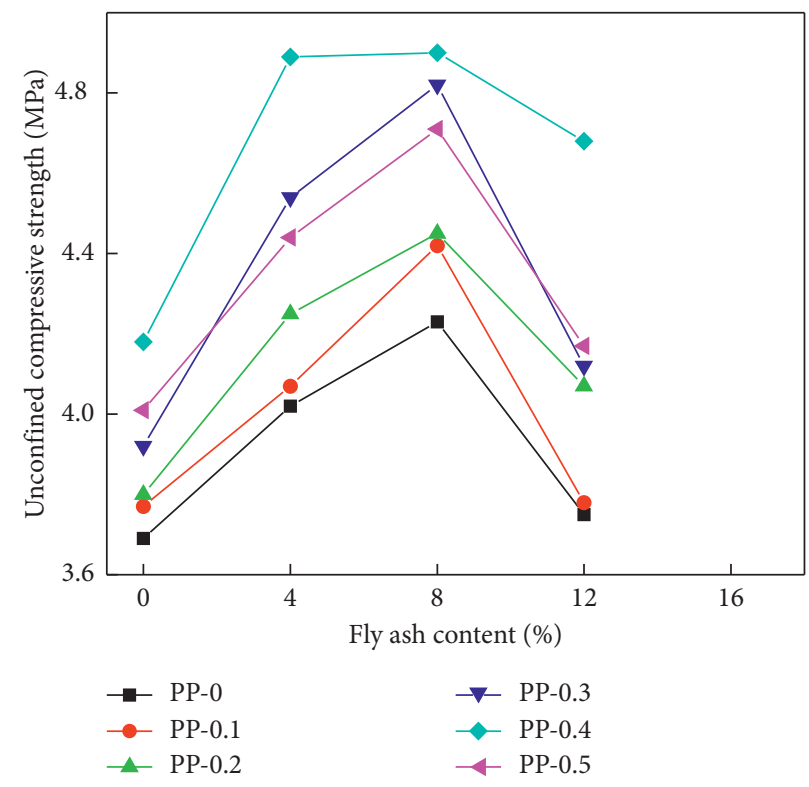

FIGURE 4: Relationship between unconfined compressive strength and fly ash content.

contents and $\sigma_{0}$ is the unconfined compressive strength of plain soil-cement.

It can be seen from Figure 4 that fly ash content plays an important role in unconfined compressive strength of soilcement. In the same polypropylene fiber content, the unconfined compressive strength of soil-cement increases with the increase of fly ash content from $0 \%$ to $8 \%$; however, further increasing fly ash content from $8 \%$ to $12 \%$ results in the decrease of unconfined compressive strength in general. Hence, the suitable inclusion of fly ash on unconfined compressive strength of soil-cement is $8 \%$ in this experiment. This experimental result is consistent with the previous study performed by He and Shen [32]. Figure 4 also shows that under the condition of $0,0.1 \%, 0.2 \%, 0.3 \%, 0.4 \%$, and $0.5 \%$ fiber inclusion, unconfined compressive strength of soilcement with $8 \%$ fly ash content increases by $14.63 \%$, $17.24 \%, 17.11 \%, 22.96 \%, 17.22 \%$, and $17.46 \%$ as compared with that of soil-cement without fly ash inclusion. At the inclusion of $12 \%$ fly ash, unconfined compressive strength decreases by $11.35 \%, 14.48 \%, 8.54 \%, 14.52 \%, 4.49 \%$, and $11.46 \%$ as compared with that of soil-cement $8 \%$ fly ash with fiber from 0 to $0.5 \%$. Under the condition of $8 \%$ fly ash inclusion, the maximum of unconfined compressive strength of soil-cement reinforced with $0.4 \%$ fiber is $4.90 \mathrm{MPa}$, increasing by $16.08 \%$ as compared with that of soil-cement without fiber inclusion. 
It is likely that fly ash can fill the fine pores between soil particles, and glass bead structure of fly ash can make the soil and fly ash mix uniformly, which makes the hydration reaction more sufficient [4]. The active substances (e.g., silica, alumina, and calcium oxide) in the fly ash react with the hydration reaction products of the cement, which forms a gel material (e.g., hydrated calcium silicate, hydrated calcium aluminate, and calcium meteorite) that is interlaced and wrapped with earthy particles. The internal bonding capacity of soil-cement is greatly enhanced, and the strength of fly ash soil-cement is improved. However, the amount of fly ash exceeds the suitable content ( $8 \%$ in the test), correspondingly reducing the amount of soil and cement, which results in the decrease of main strength provided by the particle size structure of the soil.

Figure 5 shows the variation of unconfined compressive strength of soil-cement specimens with polypropylene fiber content. From Figure 5, it can be seen that polypropylene fiber content has a significant influence on improving unconfined compressive strength for soil-cement specimens. In the same fly ash content, the unconfined compressive strength of soil-cement specimens increases with the increase of polypropylene fiber content from $0 \%$ to $0.4 \%$; however, by further increasing polypropylene fiber content from $0.4 \%$ to $0.5 \%$, the unconfined compressive strength begins to show a downward trend. Hence, the suitable inclusion of polypropylene fiber content on unconfined compressive strength of reinforced specimens is $0.4 \%$. The results are different from that of $\mathrm{Mei}$ and $\mathrm{Xu}$ [33], and their results presented that the optimum content of polypropylene fiber is $0.3 \%$ by weight of dry soil, which might be due to the difference of soil properties. In addition, the inclusion of fly ash that is glass bead structure increases the fluidity of soilcement, improving the dispersion of fiber. Under the condition of $0,4 \%, 8 \%$, and $12 \%$ fly ash inclusion, the unconfined compressive strength of soil-cement with $0.4 \%$ polypropylene fiber increases by $13.28 \%, 21.64 \%, 15.84 \%$, and $24.80 \%$ as compared with the fiber unreinforced samples. At the inclusion of $0.5 \%$ fiber, unconfined compressive strength decreases by $4.07 \%, 9.20 \%, 3.88 \%$, and $10.88 \%$ as compared with that of $0.4 \%$ polypropylene fiber soil-cement with fly ash from 0 to $12 \%$. Under the condition of $0.4 \%$ polypropylene fiber inclusion, the maximum of unconfined compressive strength of soil-cement reinforced with $8 \%$ fly ash is $4.90 \mathrm{MPa}$, increasing by $17.22 \%$ as compared with that of soil-cement without fly ash inclusion. The effect of fiber on unconfined compressive strength might be due to the following reasons:

(i) The root of the fiber is wrapped with the gel material that is the hydration reaction product of the cement, which forms an anchoring effect on the fiber.

(ii) Infiltration of hydration reaction products between fibers produces more hydrated gel material on the fiber surface [34], which increases the bonding strength between fibers and soil particles, strengthens the lateral constraint of the wrapped fiber, and improves the deformability of the fiber soil-cement.

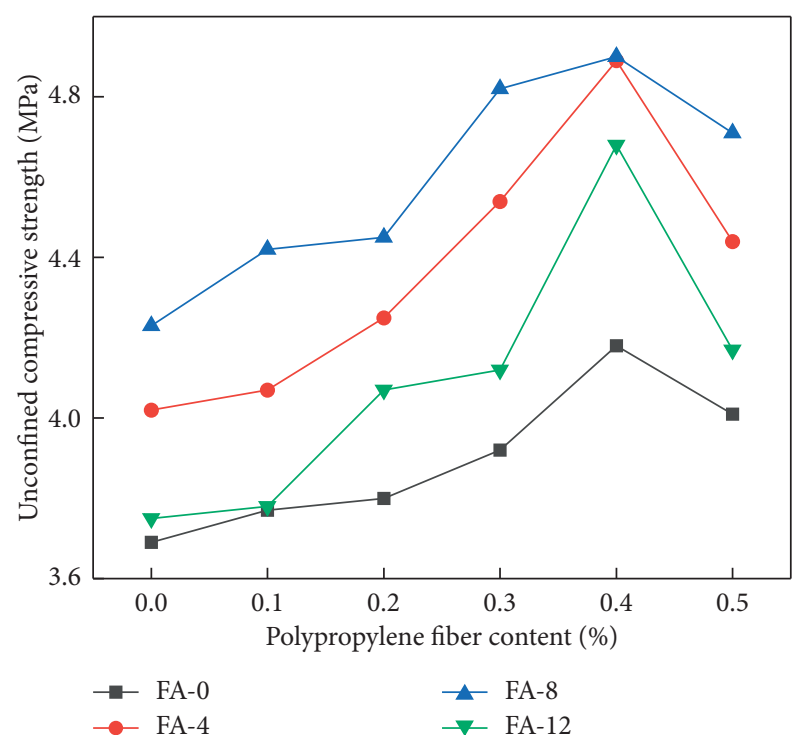

FIGURE 5: Relationship between unconfined compressive strength and polypropylene fiber content.

(iii) However, when the polypropylene fiber exceeds the optimum content $(0.4 \%$ in the test), the agglomeration of some fibers leads to a decrease in the bonding interface between fibers and soil particles. The frictional resistance and gripping force of fiber interfaces are smaller than that of fiber, soil particles, and hydration product interface [16], which greatly reduced the reinforcement of fiber.

The addition of both polypropylene fiber and fly ash tends to greatly improve unconfined compressive strength. When $8 \%$ fly ash is used, the unconfined compressive strength increased by $15.84 \%$, from $4.23 \mathrm{MPa}$ to $4.90 \mathrm{MPa}$, as polypropylene fiber increased from $0.1 \%$ to $0.4 \%$. It can be seen that the double inclusion of polypropylene fiber and fly ash can effectively improve the unconfined compressive strength of soil-cement.

3.2. Splitting Tension Test. The relationship between polypropylene fiber content, fly ash content, and splitting tensile strength of the soil-cement based on the experimental data is given in Figures 6 and 7.

Figure 6 represents the effect of polypropylene fiber on splitting tensile strength of samples. It can be observed from Figure 3 that the fiber inclusion makes contribution to the enhancement of the splitting tensile strength of soilcement. In the same fly ash content, the splitting tensile strength increases with the increase of polypropylene fiber content from $0 \%$ to $0.4 \%$, further increasing with polypropylene fiber result in the reduction of splitting tensile strength. The result is mainly attributed to the following reasons:

(i) The tensile strength of polypropylene fiber is much greater than the tensile strength of soil-cement after the tensile cracks formed, and the interaction 


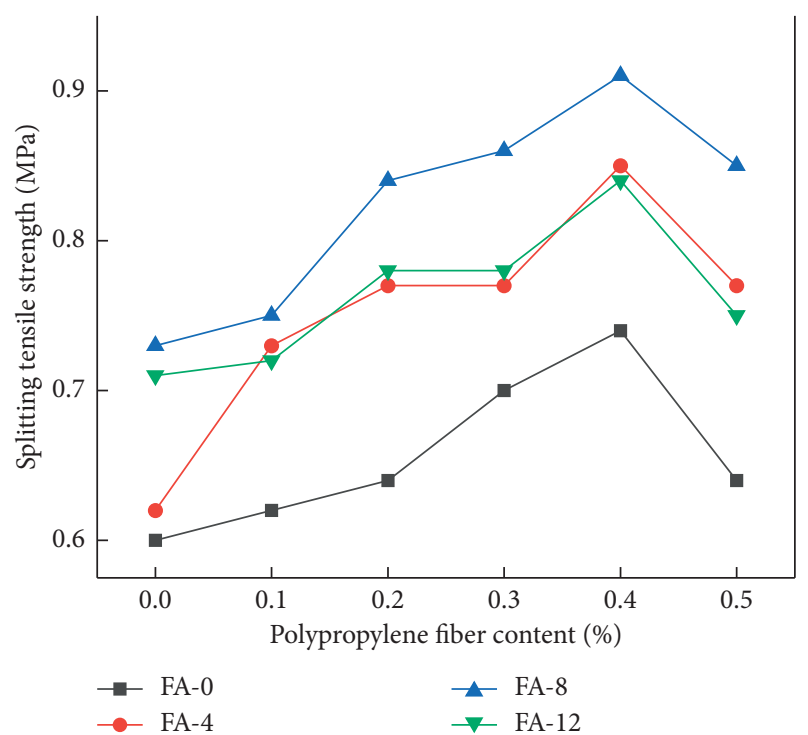

Figure 6: Relationship between splitting tensile strength and polypropylene fiber content.

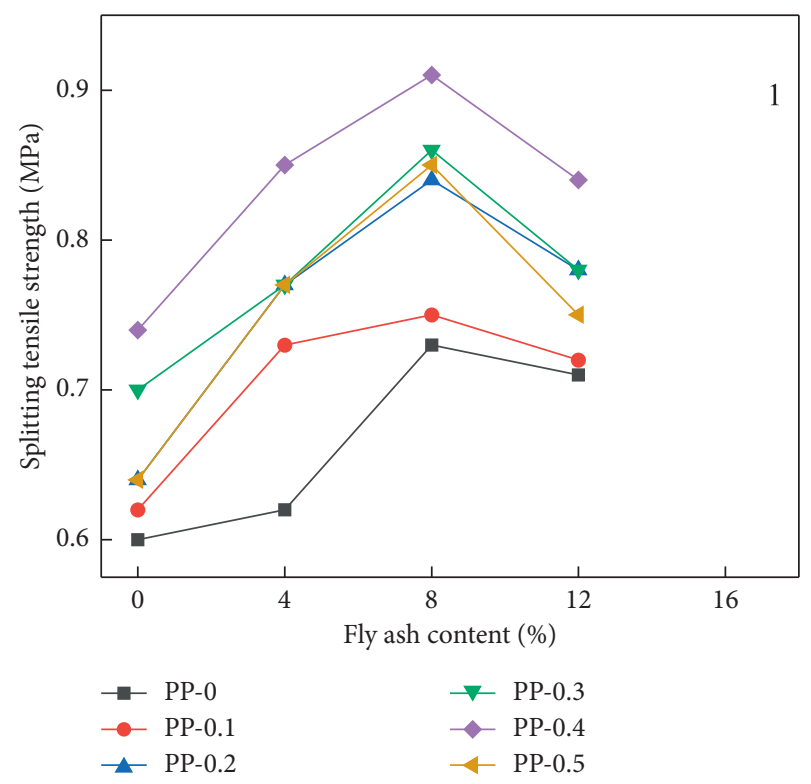

Figure 7: Relationship between splitting tensile strength and fly ash content.

between fibers and soil particles provided the tensile resistance.

(ii) The combined action between fiber and soil particles can efficiently prevent and delay the development of tensile failure plane. Under the condition of the crack further expanding, the bridging effect of polypropylene fiber reduces the stress concentration at the crack tip and bears most of the tensile stress [27].

Under the condition of $0 \%$ fly ash inclusion, the splitting tensile strength increases at a relatively slow rate within $0.2 \%$ fiber content. As the fiber content increases from $0.2 \%$ to $0.4 \%$, the splitting tensile strength increases rapidly. The splitting tensile strength of soil-cement reinforced with $0.4 \%$ fiber is the highest, which increased by $23.33 \%(0.74 \mathrm{MPa})$ as compared with that of the plain soil-cement $(0.60 \mathrm{MPa})$. The polypropylene fiber can effectively improve the splitting tensile strength of the soil-cement. Under the condition of $4 \%, 8 \%$, and $12 \%$ fly ash content, splitting tensile strength of soil-cement modified with $0.4 \%$ fiber increases by $37.10 \%$, $24.66 \%$, and $18.31 \%$ as compared with that of soil-cement without fiber, and splitting tensile strength of soil-cement modified with $0.5 \%$ fiber decreases by $9.41 \%, 6.59 \%$, and $10.71 \%$ as compared with that of soil-cement with $0.4 \%$ fiber.

Figure 7 shows the variation of splitting tensile strength of soil-cement with fly ash content. As can be seen from Figure 7 , in the same polypropylene fiber content, the splitting tensile strength increases with the increase of fly ash content from $0 \%$ to $8 \%$. However, further increasing the fly ash content results in the reduction of splitting tensile strength. This is similar to the result of unconfined compressive strength. Under the condition of $0,0.1 \%$, $0.2 \%, 0.3 \%, 0.4 \%$, and $0.5 \%$ fiber inclusion, splitting tensile strength of soil-cement modified with $8 \%$ fly ash content increases by $21.67 \%, 20.97 \%, 31.25 \%, 22.86 \%$, $22.97 \%$, and $32.81 \%$ as compared with that of soil-cement without fly ash inclusion, and splitting tensile strength of soil-cement modified with $12 \%$ fly ash decreases by $2.74 \%$, $4.00 \%, 7.14 \%, 9.30 \%, 7.69 \%$, and $11.76 \%$ as compared with that of soil-cement modified with $8 \%$ fly ash. Under the condition of $8 \%$ fly ash inclusion, the maximum of splitting tensile strength of soil-cement modified with $0.4 \%$ fiber is $0.91 \mathrm{MPa}$, increasing by $24.66 \%$ as compared with that of soil-cement without fiber inclusion. This indicates that the combined action of fly ash and polypropylene fiber can effectively increase the splitting tensile strength of soil-cement.

\section{Deformation and Failure Mode}

4.1. Deformation Characteristics. The stress-strain behaviors provide a better understanding of the deformation characteristics of soil-cement. Through the unconfined compressive strength test, the stress-strain curve of soil-cement under different polypropylene fiber and fly ash contents is obtained, as shown in Figures 8 and 9. Figure 8 presents stress-strain curve for plain soil-cement, while Figure 9 shows stress-strain curves for soil-cement with $8 \%$ fly ash and different polypropylene fiber contents. It can be seen from the figures that the stress-strain curves of polypropylene fiber-modified fly ash soil-cement and plain soilcement can be roughly divided into four stages: compaction stage $(O A)$, linear rise stage $(A B)$, nonlinear rise stage $(B C)$, and destruction stage $(C D)$.

$O A$ is a compact phase of the stress-strain curve because the pores between soil particles are compacted, which shows that the compressive strain is independent of polypropylene fiber content. At this stage, the strain growth rate is fast, and the strain of plain soil-cement and soil-cement modified with polypropylene fiber and fly ash are about 0.0110 0.0130. 


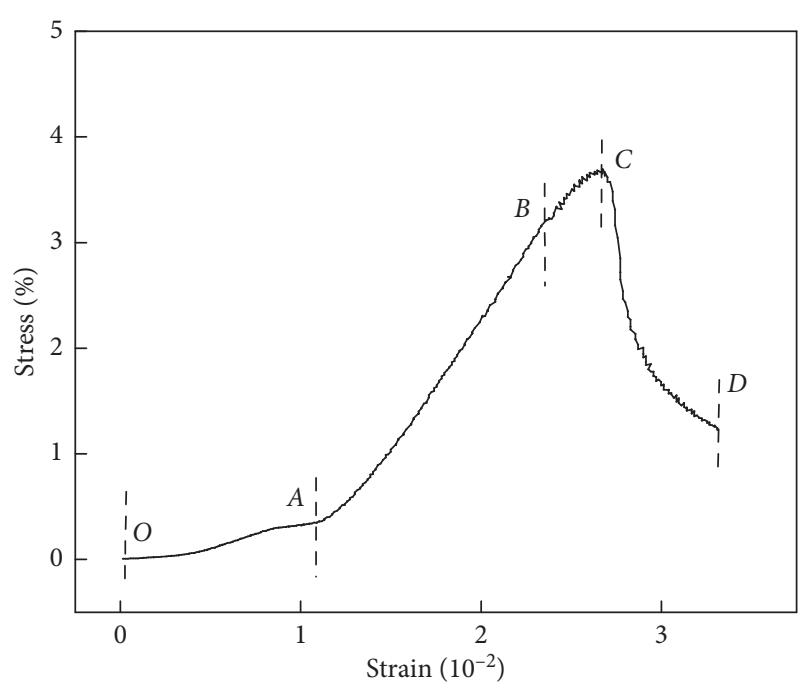

FIgURE 8: Stress-strain curve of plain soil-cement.

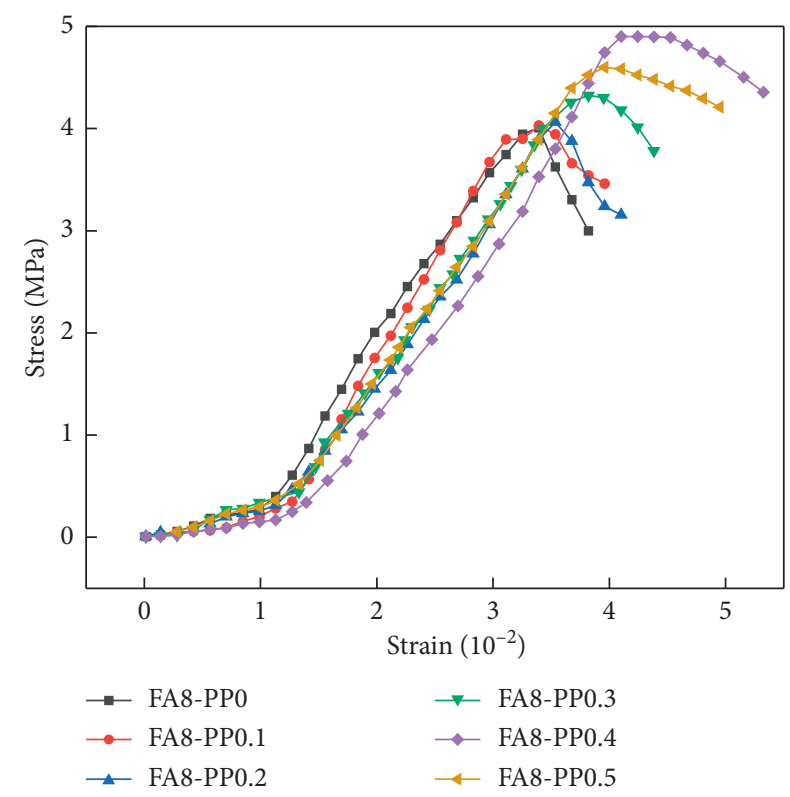

FIGURE 9: Stress-strain curve of soil-cement reinforced with different polypropylene fiber and $8 \%$ fly ash contents.

$A B$ is a linear rise phase of the stress-strain curve, which is mainly the stable development stage of soil-cement cracks. The compressive strain is related to the polypropylene fiber content. At this stage, the slope of the curve is large and the strain growth rate is reduced as compared with that of $O A$. The slope of the soil-cement with fiber inclusion is smaller than that of the plain soil-cement, and the maximum linear strain of the plain soil-cement is about 0.0233. Under the condition of $8 \%$ fly ash, the maximum linear strains of the soil-cement modified with $0.1 \%, 0.2 \%, 0.3 \%, 0.4 \%$, and $0.5 \%$ fiber are approximately $0.0297,0.0311,0.0325,0.0356$, 0.0382 , and 0.0367 . It can be found that the inclusion of fiber can increase the maximum linear strain. However, when the fiber content exceeds $0.4 \%$, the maximum linear strain decreases. At this stage, the soil-cement with fiber inclusion mainly plays a lateral restraining role in delaying the development of internal cracks in soil-cement and increasing the maximum linear strain. When the fiber content is appropriate $(0.1 \%-0.4 \%$ in this test), the maximum linear strain increases with the increase of fiber content due to fiber restriction effect. However, when the fiber exceeds the critical amount ( $0.4 \%$ in this test), the fiber causes a decrease in lateral restraint due to agglomeration, which in turn reduces the maximum linear strain.

$B C$ is a nonlinear rising phase of the stress-strain curve, which is mainly the accelerated expansion stage of soilcement cracks. At this stage, the stress and strain are nonlinear and the strain growth rate is faster as compared with that of $A B$. The peak strain of plain soil-cement is about 0.0267 , and the peak strain of soil-cement modified with $0.1 \%, 0.2 \%, 0.3 \%, 0.4 \%$, and $0.5 \%$ fiber is $0.0342,0.0354$, $0.0382,0.0410$, and 0.0396 under the condition of $8 \%$ fly ash. It can be found that the inclusion of fibers can increase the peak strain. The fiber mainly acts as a bridging effect to lower the stress concentration at the crack tip, which inhibits the crack development and increases the peak strain. However, when the fiber exceeds the critical content ( $0.4 \%$ in this test), the fiber bridging effect is lowered, which causes the decrease of the peak strain.

$C D$ is the failure stage of the stress-strain curve. After the strain reaches the peak value, the curve shows a downward trend, which shows that the bearing capacity decreases. At this stage, the stress-strain curve is bent downward, and the plain soil-cement exhibits obvious brittle failure characteristics. The postpeak strain of the fiber modified soilcement is flatter than that of the plain soil-cement, showing a certain ductility characteristic. In addition, the curve gradually flattens with the increase of the fiber content.

4.2. Elastic Modulus. Modulus is employed to evaluate the ability of soil to resist deformation [35]. Modulus of soil based on the unconfined compression test has been investigated by many researchers. As can be seen from Figure 9 , the stress-strain curves of soil-cement modified with different polypropylene fibers and $8 \%$ fly ash change nonlinearly. The elastic modulus $E$ is also different due to the difference of intercepted line segment on the curve. According to the literature written by Tang et al. [36], modulus can be obtained from the linear portion of stressstrain curve. From Figure 9, the connecting line segments of $A B$ are selected as the research object in the experiment. Elastic modulus can be expressed by following formula:

$$
E=\frac{\Delta \sigma}{\Delta \varepsilon}=\frac{\sigma_{B}-\sigma_{A}}{\varepsilon_{B}-\varepsilon_{A}},
$$

where $\sigma_{A}$ and $\sigma_{B}$ are the stress of $A$ and $B$ corresponding to the strain $\varepsilon_{A}$ and $\varepsilon_{B}$ from Figures 8 and 9.

Figure 10 shows that there is a certain fluctuation in the elastic modulus. Under the condition of $0.1 \%$ fiber, elastic modulus increases by $11.78 \%(192.8 \mathrm{MPa})$ as compared with the fiber unreinforced soil-cement (172.4 MPa). Elastic modulus, with increasing fiber content from $0.1 \%$ to $0.3 \%$, 


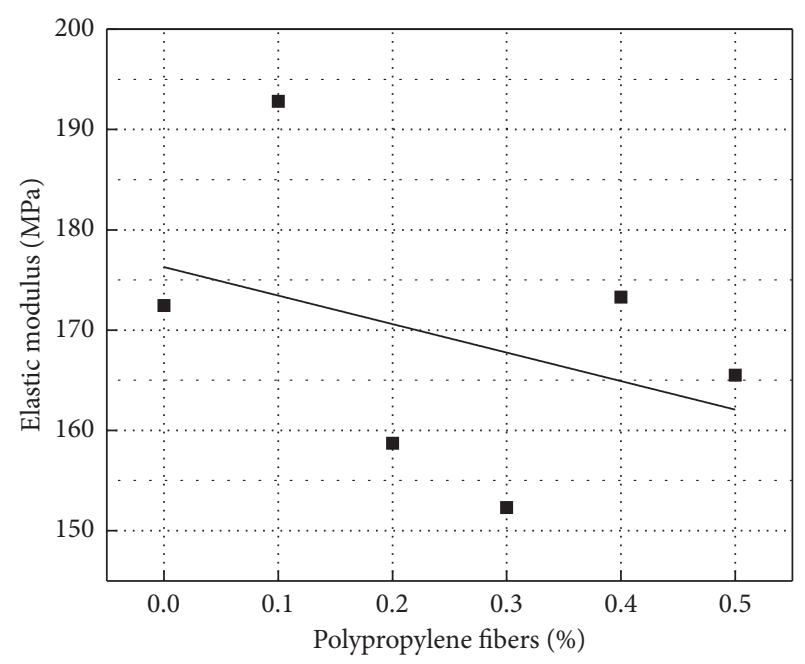

FIGURE 10: Elastic modulus diagram of soil-cement reinforced with different polypropylene fiber and $8 \%$ fly ash contents.

ranges from 192.8 $\mathrm{MPa}$ to $152.3 \mathrm{MPa}$. Compared with the fiber from $0.1 \%$ to $0.3 \%$, elastic modulus has a smaller fluctuation with the fiber from $0.3 \%$ to $0.5 \%$. It is known by curve fitting that the elastic modulus decreases with the increase of fiber in general. The result is similar to the conclusions drawn by Park [22], Gullu and Khudir [25], and $\mathrm{Li}$ et al. [37]. The main reason may be that the fiber reduces the contact behaviors between cement and soil particles.

4.3. Peak Strain. The peak strain diagram of soil-cement modified with different polypropylene fibers and $8 \%$ fly ash contents, as shown in Figure 11, is obtained by the splitting tension test. It can be seen from Figure 11 that the splitting tensile peak strains of soil-cement modified with $0.1 \%, 0.2 \%$, $0.3 \%, 0.4 \%$, and $0.5 \%$ polypropylene fibers are 0.0140 , $0.0156,0.0168,0.0196$, and 0.0172 , respectively, which increases by $20.69 \%, 34.48 \%, 44.83 \%, 68.97 \%$, and $48.28 \%$ as compared with that without fibers inclusion. Due to the reinforcement of the fiber, the splitting tensile peak strain was significantly improved. From Figure 11, it can also be concluded that $0.4 \%$ polypropylene fiber in the test has the best ability to resist deformation.

4.4. Failure Mode. The failure mode of soil-cement was studied by unconfined compression test. The final failure mode of soil-cement samples with different polypropylene fiber contents is shown in Figure 12.

The damage of the plain soil-cement is cracked from the diagonal, gradually expanding to the middle, which results in the surface clod of soil-cement falling off and the soilcement sample destroyed, as shown in Figure 12(a). When the fiber content is from $0.1 \%$ to $0.4 \%$, the crack width becomes thinner with the increase of fiber content, and the crack failure changes from coarse and small to fine and dense, as shown in Figures 12(b), 12(c), 12(d), and 12(e). Because the fiber can be uniformly dispersed into the soilcement, the mesh constraint on soil particles is gradually

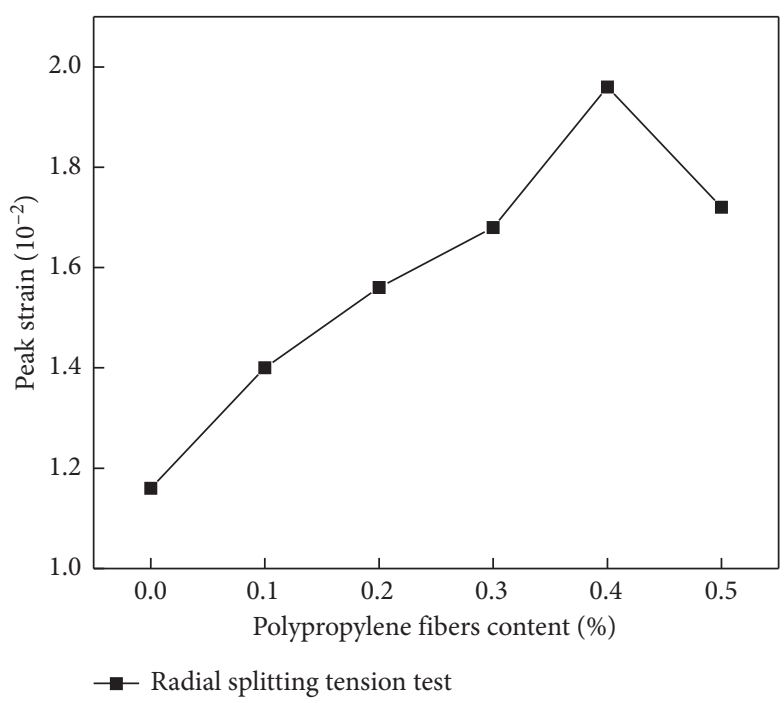

FIGURE 11: Peak strain diagram of soil-cement reinforced with different polypropylene fiber and $8 \%$ fly ash contents.

increased as the fiber content increases, inhibiting the development of the crack initiation. When the fiber content reaches $0.5 \%$, the fiber agglomerates in the soil-cement. Because the frictional resistance between fibers is smaller as compared with that between fiber and soil particle, the crack develops and gradually destroys from the fiber agglomeration, as shown in Figure 12(f). From the point of view of the failure mode, the reasonable content of fiber is $0.4 \%$ in the experiment.

\section{Analysis of SEM Images of Specimens}

5.1. Effect of Fly Ash Content. Figure 13 shows SEM images of soil-cement samples modified with different fly ash contents. It can be seen from Figures 13(a), 13(b), 13(c), and 13(d) that specimens exhibit cracks and pores in the soilcement matrix, which were probably caused during the mechanical test. Cement creates strong bonds between soil particles. In addition, there are many fine threads (Figures 13(c) and 13(h)) on the soil-cement matrix surface, which corresponds to ettringite products and calcium silicate hydrates (C-S-H) gel formed from the hydration reactions of cement [34]. C-S-H gel has a larger specific surface area as compared with soil particles wrapped by C-S-H gel, which gives rise to have a larger specific energy and adsorption energy. The effect of fly ash on soil-cement samples is shown in Figure 13(c). The glass bead structure of the fly ash is clearly observed, which can fill the internal voids of the soil-cement and make the internal structure denser. Figures 13(e), 13(f), and $13(\mathrm{~g})$ show that the connection between soil particles is changed from contact connection to glue connection. The pores between soil particles are decreasing and the structure changes from chaotic disorder to a regularly arranged flaky. However, the excessive fly ash (12\%) cannot react with soil particles completely. Given that fly ash is a nonstick material, the unreacted fly ash particles of soil-cement will reduce the 


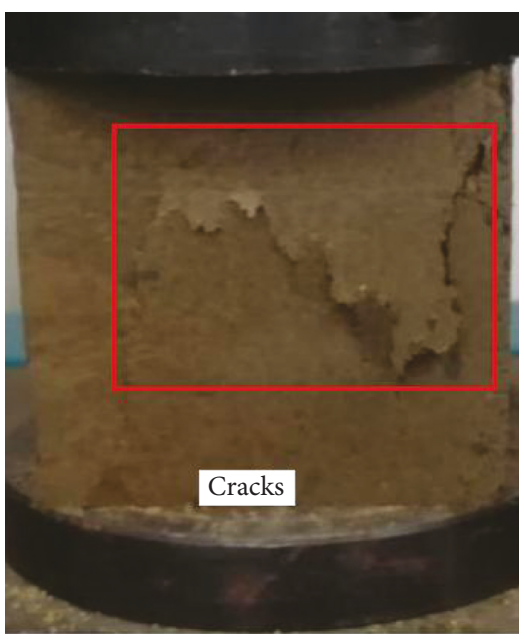

(a)

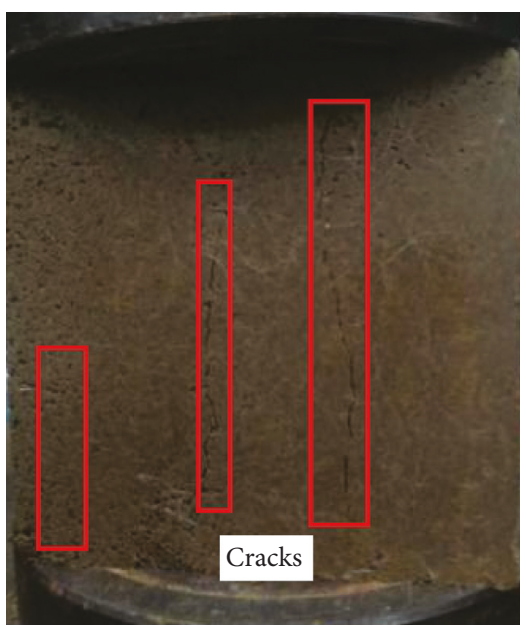

(d)

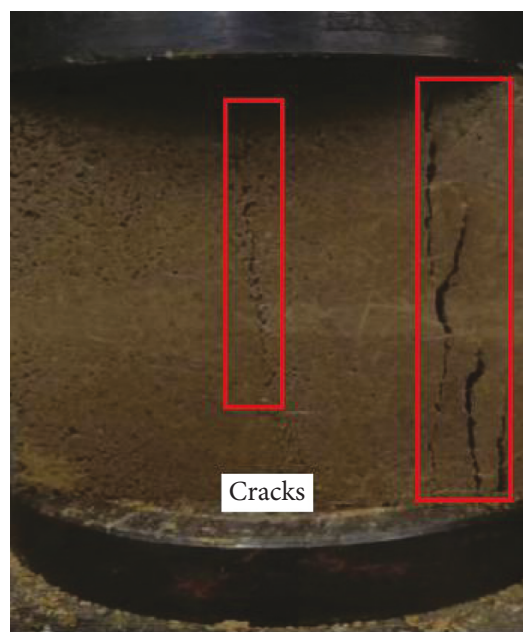

(b)

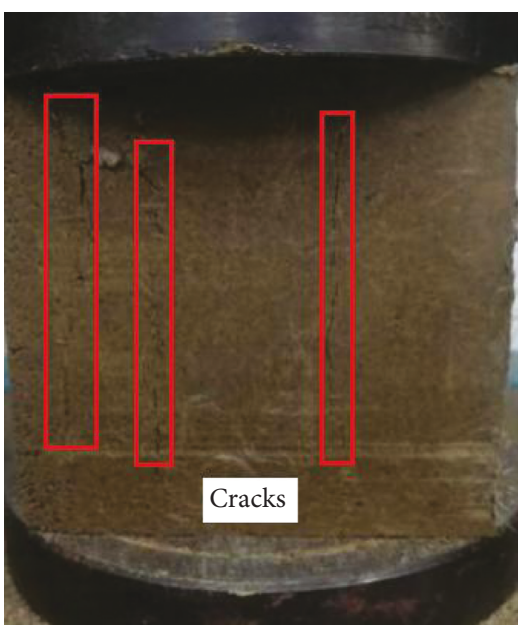

(e)

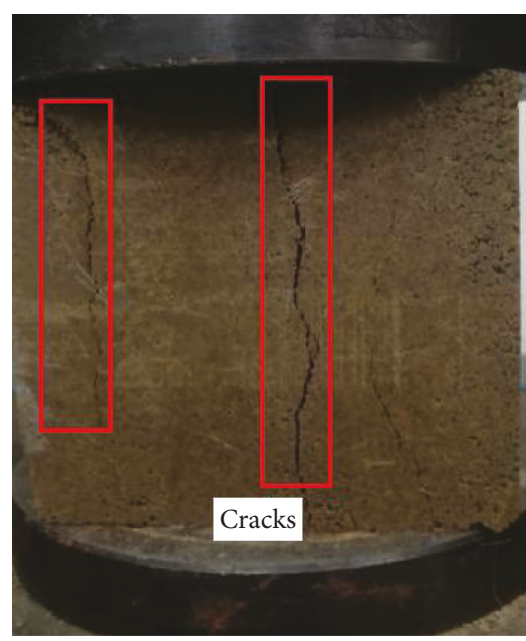

(c)

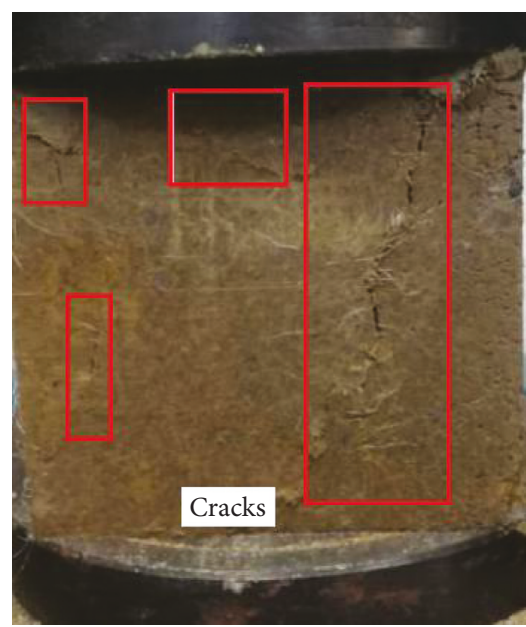

(f)

FIGURE 12: The final failure mode of soil-cement with different polypropylene fiber contents. (a) FA-0\%, PP-0\%. (b) FA-0\%, PP-0.1\%. (c) FA- $0 \%$, PP- $-2 \%$. (d) FA-0\%, PP-0.3\%. (e) FA- $0 \%$, PP- $0.4 \%$. (f) FA- $0 \%$, PP- $0.5 \%$.

interparticle connection and the bonding force between soil particles, which decreases the unconfined compressive strength of soil-cement modified with fly ash (12\%) accordingly in previous tests, as shown in Figure 13(i).

5.2. Effect of Polypropylene Fiber Content. Figure 14 shows SEM images of the effect of soil-cement reinforced with polypropylene fiber. Figure 14(a) depicts SEM image of specimens unreinforced with polypropylene fiber, which exhibits pores and cracks in the soil-cement matrix and appears disordered. Figures 14(b), 14(c), and 14(d) show SEM images of specimens reinforced with $0.4 \%$ polypropylene fiber under different magnifications. It can be seen from Figures 14(b), 14(c), and 14(d) that the polypropylene fibers having a rough surface are tightly wrapped by the remains of affixed material on the fiber surface, which presents better adhesion between matrix and fibers. The pores between matrix and polypropylene fiber could be generated during the mechanical test.
Figure 15 shows the schematic diagram of the friction between polypropylene fiber and soil-cement. It is supposed that the length of polypropylene fiber is $d l$ and the weights of fiber and soil-cement are ignored. The fiber is subjected to axial tension $F_{1}, F_{2}$ from external loads and normal stress $N$ from soil particles and hydration products. The tension $d F$ on the microsegment is defined as

$$
d F=F_{1}-F_{2} .
$$

The friction $d T$ between the fiber and the soil and the hydration product is defined as

$$
d T=2 N \cdot \mu \cdot d s,
$$

where $\mu$ is the coefficient of friction and $d s$ is microsection area corresponding to the length of $d l$.

As can be seen from the above formula, if $d T>d F$, that is, the friction between the fiber and the soil, the hydration products can resist fiber tension caused by external loads. Polypropylene fiber has high elastic modulus and excellent tensile strength, which prevents the fiber from being pulled 


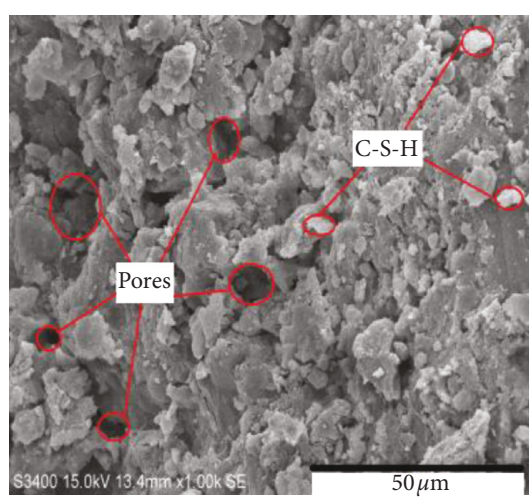

(a)

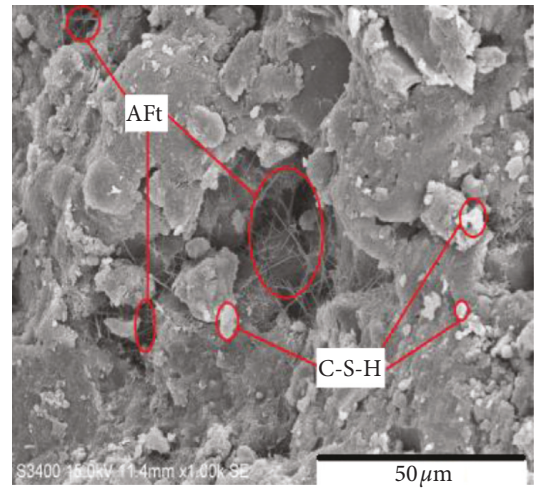

(d)

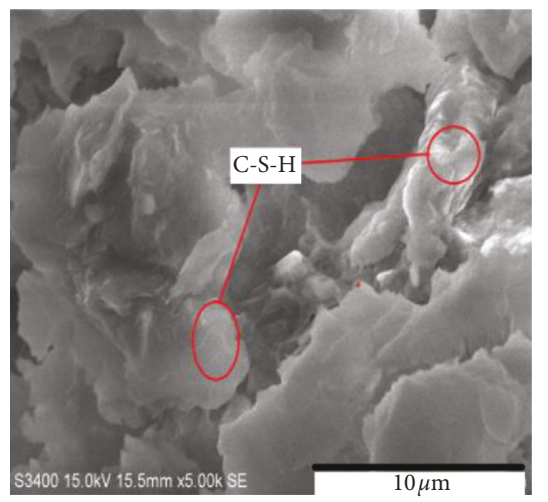

(g)

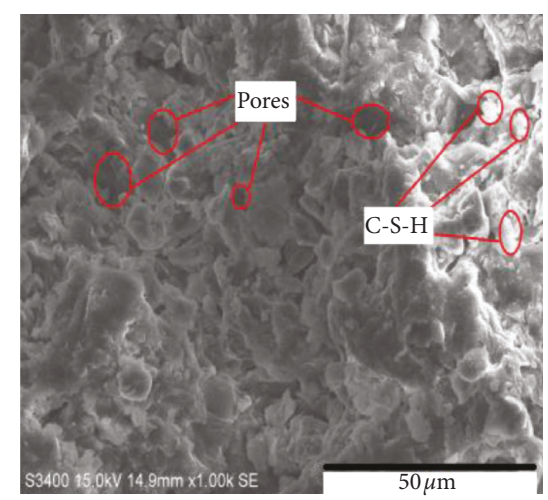

(b)

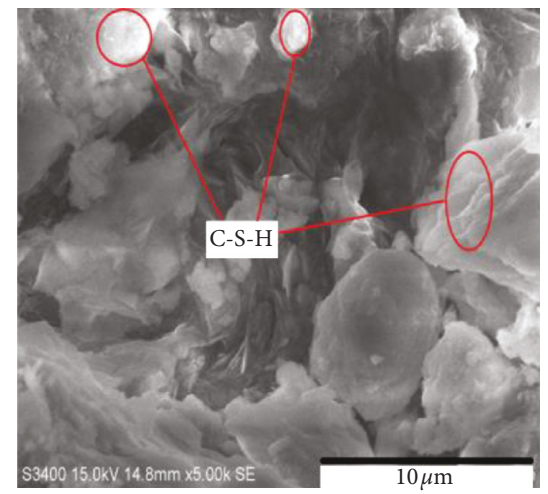

(e)

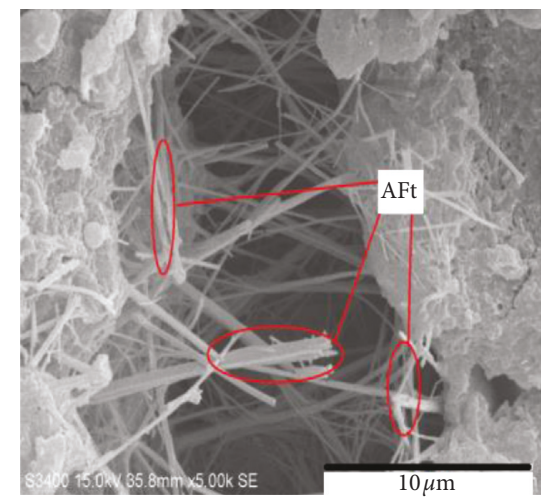

(h)

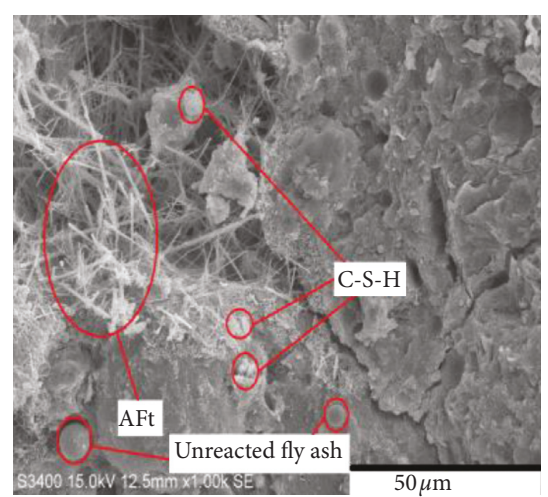

(c)

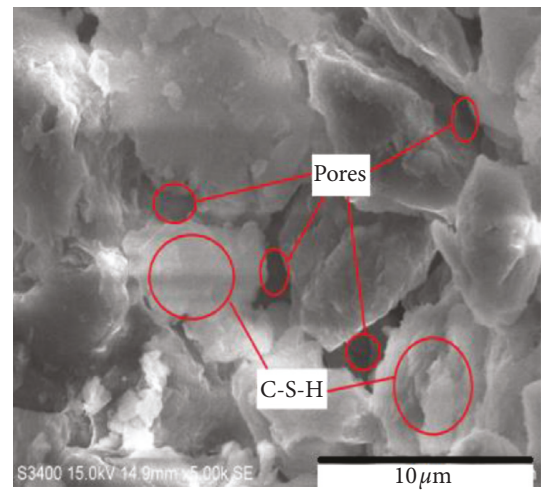

(f)

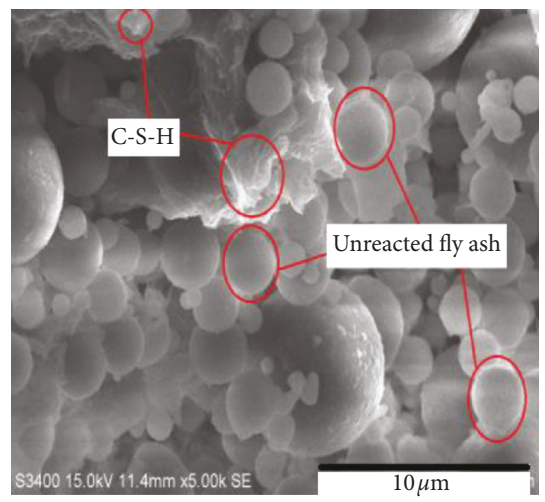

(i)

FIGURE 13: SEM images of soil-cement samples reinforced with different fly ash contents. (a) $0 \%$ fly ash $(\times 1000)$. (b) $4 \%$ fly ash $(\times 1000)$. (c) $8 \%$ fly ash $(\times 1000)$. (d) $12 \%$ fly ash (×1000). (e) $0 \%$ fly ash $(\times 5000)$. (f) $4 \%$ fly ash $(\times 5000)$. (g) $8 \%$ fly ash $(\times 5000)$. (h) $12 \%$ fly ash ( $\times 5000)$. (i) $12 \%$ fly ash $(\times 5000)$.

off under external loads. The fiber is wrapped by the hydration products, increasing the friction between the fiber and the soil and hydration products. The above theory explains the reason why fiber improves the strength of soilcement from the perspective of friction [38, 39].

Figure 16 shows interface diagram of soil-cement reinforced with fibers. According to the interface wetting theory [34], the fibers and the soil particles are mainly infiltrated and mechanically connected. It can be seen from Figure 16 that the polypropylene fibers are randomly distributed in the soil-cement, and the roots of the fibers are wrapped by the hydration products, which forms an anchoring effect. The infiltration of the fiber causes more hydration gel material on the surface, and the infiltration of the hydration products between the fibers increases the strong bonds between soil particles, increasing the lateral constraint on fibers. This theory explains the reason why fiber increases the strength of soil-cement from the perspective of interface theory.

\section{Conclusions}

In this article, unconfined compression test, splitting tension test, and SEM test are conducted to investigate mechanical 


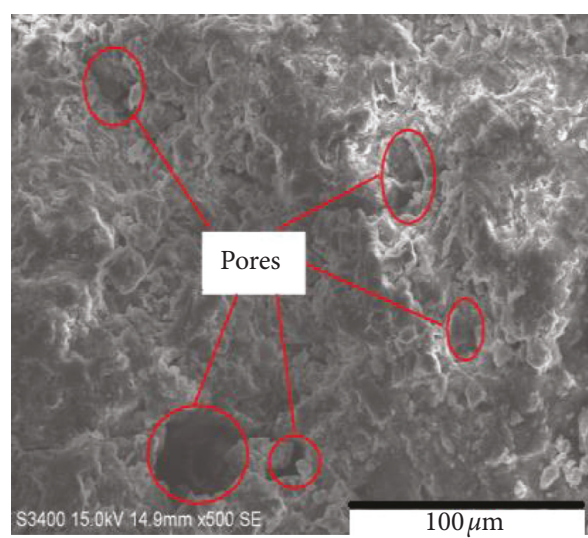

(a)

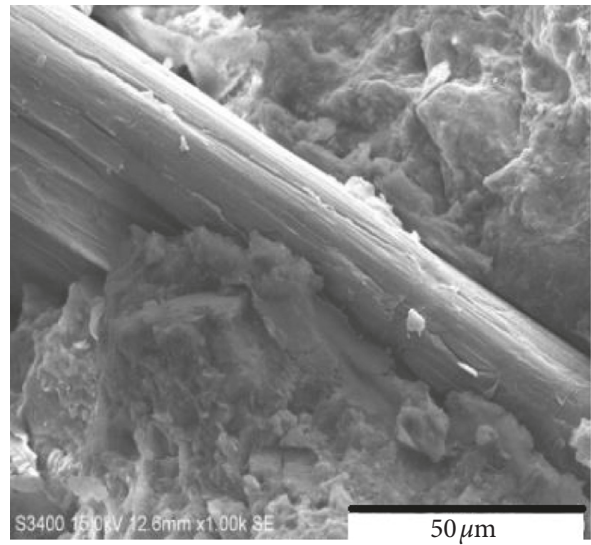

(c)

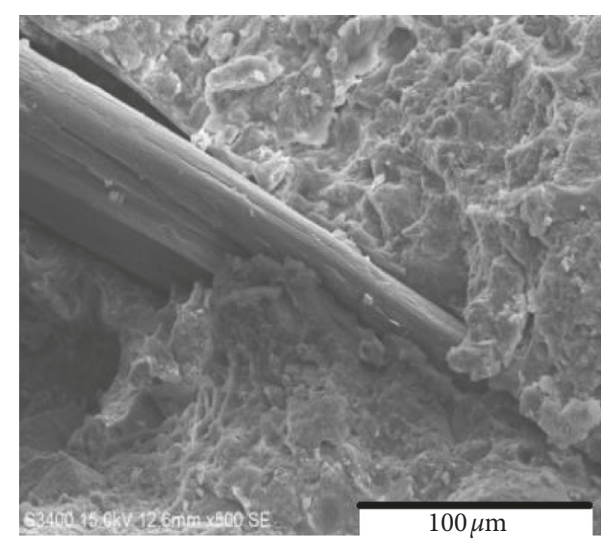

(b)

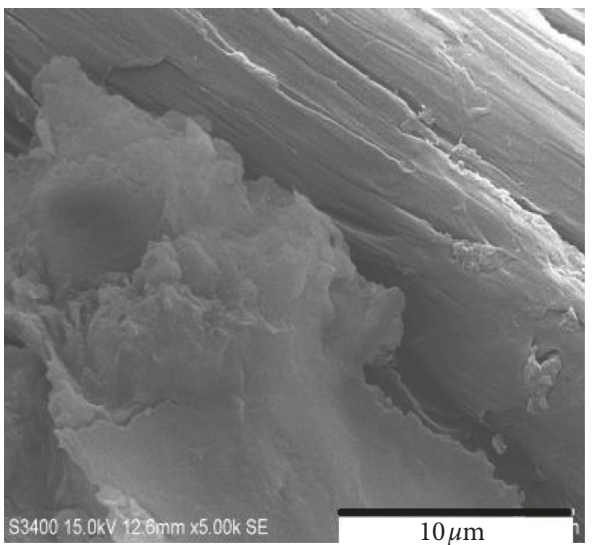

(d)

FIGURE 14: Effect of fiber reinforcement on microstructure of stabilized soil-cement. (a) Without polypropylene fiber ( $\times 500)$. (b) With $0.4 \%$ polypropylene fiber $(\times 500)$. (c) With $0.4 \%$ polypropylene fiber $(\times 1000)$. (d) With $0.4 \%$ polypropylene fiber $(\times 5000)$.

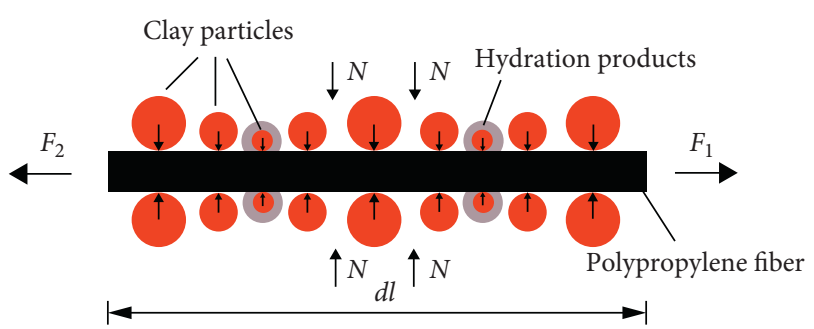

FIGURE 15: The schematic diagram of the friction between polypropylene fiber and soil-cement.

properties, deformation characteristic, failure mode, and microstructure of soil-cement modified with fly ash and polypropylene fiber. The main findings based on the study results can be summarized as follows:

(1) With the increase of fly ash content and polypropylene fiber content, the unconfined compressive strength and splitting tensile strength of soil-cement modified polypropylene fiber and fly ash increased first and then decreased. Under the conditions of $0.4 \%$ polypropylene fiber and $8 \%$ fly ash content, the unconfined compressive strength and splitting tensile strength of the soil-cement are the maximum,

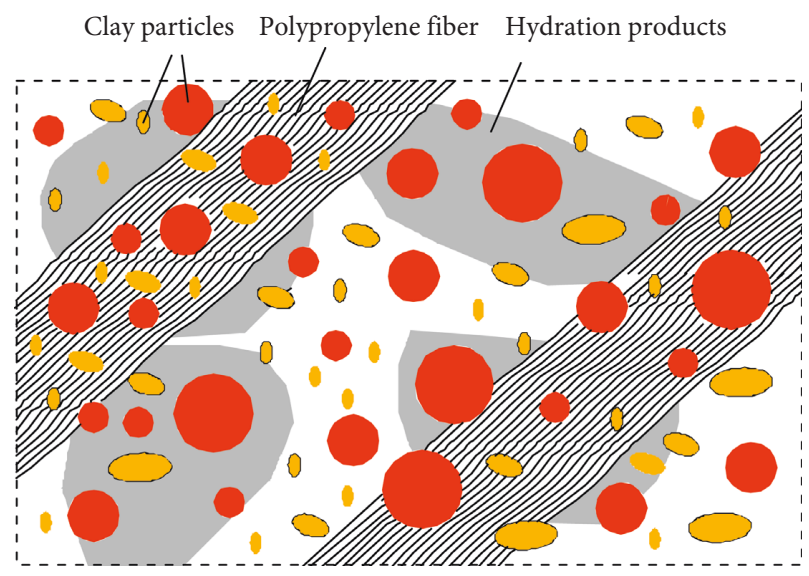

FIGURE 16: Interface diagram of soil-cement reinforced with fibers.

which is $32.8 \%$ and $51.7 \%$ higher than that of the plain soil-cement.

(2) Polypropylene fiber can effectively improve the peak strain of fly ash soil-cement. Under the conditions of $0.4 \%$ polypropylene fiber and $8 \%$ fly ash content, the unconfined compressive peak strain and splitting tensile peak strain compared to that of without fibers 
inclusion were increased by $20.94 \%$ and $68.97 \%$, respectively.

(3) The stress-strain curve of soil-cement modified with polypropylene fiber and fly ash can be divided into compaction stage, linear rising stage, nonlinear rising stage, and failure stage. The transverse reinforcement of polypropylene fiber restrains the fiber soil-cement deformation ability and improved the failure mode of fiber soil-cement.

\section{Data Availability}

The data used to support the findings of this study are available from the corresponding author upon request.

\section{Conflicts of Interest}

The authors declare that they have no conflicts of interest regarding the publication of this paper.

\section{Acknowledgments}

This research was funded by the Natural Science Research Project of Colleges and Universities in Anhui Province (no. KJ2015A135). The authors are grateful to the Engineering Research Center of Underground Mine Construction, Ministry of Education, and Anhui University of Science and Technology for providing the experiment conditions.

\section{References}

[1] Y. Liu, J. Hu, Y.-P. Li, and L.-H. Li, "Statistical evaluation of the overall strength of a soil-cement column under axial compression," Construction and Building Materials, vol. 132, pp. 51-60, 2017.

[2] K. Yao, Q. Chen, J. Ho, H. Xiao, and F. H. Lee, "Straindependent shear stiffness of cement-treated marine clay," Journal of Materials in Civil Engineering, vol. 30, no. 10, article 04018255, 2018.

[3] T. Zhang, G. Cai, and S. Liu, "Reclaimed lignin-stabilized silty soil: undrained shear strength, atterberg limits, and microstructure characteristics," Journal of Materials in Civil Engineering, vol. 30, no. 11, article 04018277, 2018.

[4] P. Kumar and S. P. Singh, "Fiber-reinforced fly ash subbases in rural roads," Journal of Transportation Engineering, vol. 134, no. 4, pp. 171-180, 2008.

[5] F. Chen, "Strength and deformation characteristics of basalt fiber cement-soil at early age," Journal of Shenzhen University Science and Engineering, vol. 34, no. 6, pp. 611-617, 2017, in Chinese.

[6] J. J. Li and R. W. Liang, "Experimental study on compressive strength and deformation modulus of cement soil," Rock and Soil Mechanics, vol. 30, no. 2, pp. 473-477, 2009, in Chinese.

[7] R. N. Yong and V. R. Ouhadi, "Cemented sands under static loading," Joural of Geotechnical Engineering Division, vol. 107, no. 6, pp. 799-817, 1981.

[8] M. Khemissa and A. Mahamedi, "Key parameters for strength control of artificially cemented soil," Journal of Geotechnical and Geoenvironmental Engineering, vol. 133, no. 2, pp. 197205, 2007.
[9] R. Yong and V. Ouhadi, "Experimental study on instability of bases on natural and lime/cement-stabilized clayey soils," Applied Clay Science, vol. 35, no. 3-4, pp. 238-249, 2007.

[10] M. Khemissa and A. Mahamedi, "Cement and lime mixture stabilization of an expansive overconsolidated clay," Applied Clay Science, vol. 95, pp. 104-110, 2014.

[11] Y. H. Yang, Y. H. Liu, and X. Ren, "Experimental study on factors affecting the strength of cement-stirred saturated loess," Journal of Railway Engineering, vol. 33, no. 31, pp. 21-25+64, 2016, in Chinese.

[12] C. Q. Jia, M. S. Huang, and H. Yao, "Experimental study on soft clay strengthened in the minjiang estuary by cement-fly ash," Journal of Tongji University (Natural Science), vol. 32, no. 7, pp. 884-888, 2004, in Chinese.

[13] X. J. Liu, W. Wang, and L. L. Liu, "Utilization of fly ash resources and industrial development," Inorganic Chemicals Industry, vol. 50, no. 5, pp. 12-14, 2018, in Chinese.

[14] H. Danso, D. B. Martinson, M. Ali, and J. B. Williams, "Physical, mechanical and durability properties of soil building blocks reinforced with natural fibres," Construction and Building Materials, vol. 101, pp. 797-809, 2015.

[15] V. Sharma, H. K. Vinayak, and B. M. Marwaha, "Enhancing compressive strength of soil using natural fibers," Construction and Building Materials, vol. 93, pp. 943-949, 2015.

[16] F. Chen, "Experiment research on tensile strength of basalt fiber cement-soil," Journal of Shenzhen University Science and Engineering, vol. 33, no. 2, pp. 188-193, 2016, in Chinese.

[17] Y. J. Zhang, S. X. Yu, F. Ling, W. P. Yan, X. Liu, and P. Chen, "Experimental study on soft soil reinforced by asbestos fiber fly ash cement," Journal of Engineering Geology, vol. 23, no. 5, pp. 982-988, 2015, in Chinese.

[18] K. Q. Tran, T. Satomi, and H. Takahashi, "Improvement of mechanical behavior of cemented soil reinforced with waste cornsilk fibers," Construction and Building Materials, vol. 178, no. 30, pp. 204-210, 2018.

[19] D. Maskell, A. Heath, and P. Walker, "Inorganic stabilisation methods for extruded earth masonry units," Construction and Building Materials, vol. 71, pp. 602-609, 2014.

[20] P. Zak, T. Ashour, A. Korjenic, S. Korjenic, and W. Wu, "The influence of natural reinforcement fibers, gypsum and cement on compressive strength of earth bricks materials," Construction and Building Materials, vol. 106, pp. 179-188, 2016.

[21] L. H. Li, C. Wan, L. F. Mei et al., "Study on unconfined compressive strength of glass fiber soil-cement," Journal of Wuhan University (Engineering Science Edition), vol. 51, no. 3, pp. 252-256, 2018, in Chinese.

[22] S.-S. Park, "Unconfined compressive strength and ductility of fiber-reinforced cemented sand," Construction and Building Materials, vol. 25, no. 2, pp. 1134-1138, 2011.

[23] Z. S. Tang and K. Gu, "Strength characteristics of soft soil reinforced by polypropylene fiber and cement," China Civil Engineering Journal, vol. 44, no. S2, pp. 5-8, 2011.

[24] N. C. Consoli, R. R. de Moraes, and L. Festugato, "Parameters controlling tensile and compressive strength of fiber-reinforced cemented soil," Journal of Materials in Civil Engineering, vol. 25, no. 10, pp. 1568-1573, 2013.

[25] H. Gullu and A. Khudir, "Effects of freeze-thaw cycles on mechanical properties of polypropylene fiber and cement stabilized clay," Cold Regions Science and Technology, vol. 154, pp. 155-165, 2018.

[26] P. Y. Zhang, B. Bai, and S. C. Jiang, "Unconfined compressive strength of polyacrylamide modified sand-mixed hybrid fiber 
soil-cement," China Railway Science, vol. 35, no. 6, pp. 7-14, 2014.

[27] D. A. Gutiérrez-Orrego, E. F. Garcia-Aristizabal, and M. A. GomezBotero, "Mechanical and physical properties of soil-cement blocks reinforced with mineral wool and sisal fiber," Journal of Materials in Civil Engineering, vol. 29, no. 3, article 04016225, 2016.

[28] S. Horpibulsuk, R. Rachan, A. Chinkulkijniwat, Y. Raksachon, and A. Suddeepong, "Analysis of strength development in cement-stabilized silty clay from microstructural considerations," Construction and Building Materials, vol. 24, no. 10, pp. 2011-2021, 2010.

[29] M. Al-Mukhtar, S. Khattab, and J.-F. Alcover, "Microstructure and geotechnical properties of lime-treated expansive clayey soil," Engineering Geology, vol. 139-140, pp. 17-27, 2012.

[30] W. T. Pang, Blenging Fly Ash Compound Cement Soil Mechanical Properties and Durability Research, Inner Mongolia Agricultural University, Hohhot, China, 2013.

[31] Ministry of Transport of the People's Republic of China, Test Methods of Materials Stabilized with Inorganic Binder for Highway Engineering (JTG E51-2009), China Communications Press, Beijing, China, 2009, in Chinese.

[32] W. X. He and X. D. Shen, "Mechanical properties of glass fiber fly ash cement soil," Journal of Highway and Transportation Research and Development, vol. 29, no. 3, pp. 12-16, 2012, in Chinese.

[33] L. F. Mei and G. L. Xu, "Preparation and mechanical properties of light polystyrene foam particles light soil," Journal of Composite Materials, vol. 33, no. 10, pp. 2355-2362, 2016, in Chinese.

[34] F. Lu, Study on Mix Design and Mechanism of Fiber Asphalt Crushed Stone Stress Absorption Layer, Chang'an University, Xi'an China, 2011.

[35] B. R. Phanikumar and R. S. Sharma, "Volume change behavior of fly ash-stabilized clays," Journal of Materials in Civil Engineering, vol. 19, no. 1, pp. 67-74, 2007.

[36] L. Tang, S. Cong, L. Geng, X. Ling, and F. Gan, “The effect of freeze-thaw cycling on the mechanical properties of expansive soils," Cold Regions Science and Technology, vol. 145, pp. 197-207, 2018.

[37] L. Li, W. Shao, Y. Li, and B. Cetin, "Effects of climatic factors on mechanical properties of cement and fiber reinforced clays," Geotechnical and Geological Engineering, vol. 33, no. 3, pp. 537-548, 2015.

[38] M. Ding, F. Zhang, X. Ling, and B. Lin, "Effects of freeze-thaw cycles on mechanical properties of polypropylene fiber and cement stabilized clay," Cold Regions Science and Technology, vol. 154, pp. 155-165, 2018.

[39] Y. Z. Cao, Experimental Study on Mechanical Properties of Polypropylene Fiber Silica Fume Cement Soil, Inner Mongolia Agricultural University, Hohhot, China, 2011. 


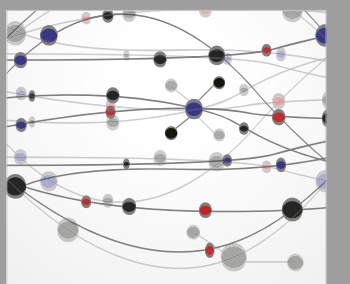

The Scientific World Journal
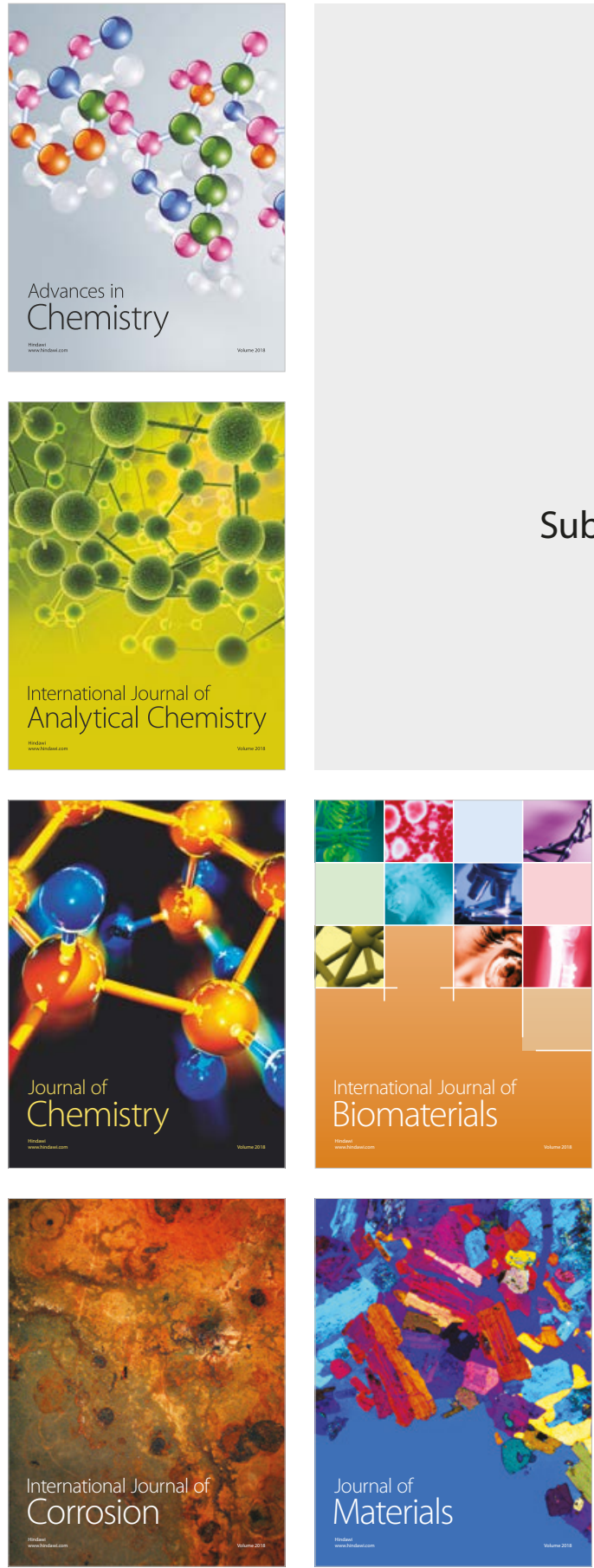

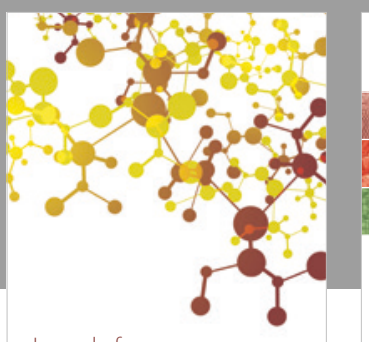

Journal of

Applied Chemistry
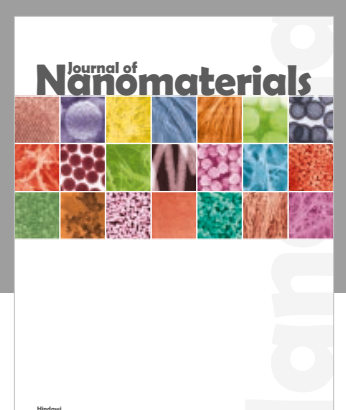

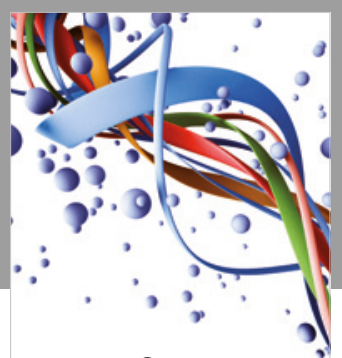

Scientifica

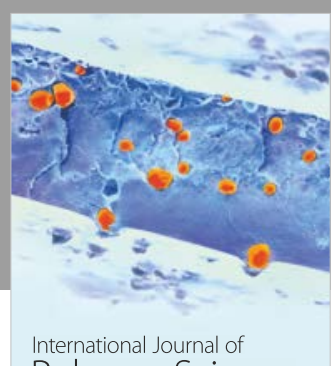

Polymer Science

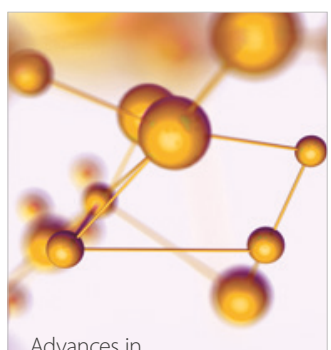

Physical Chemistry
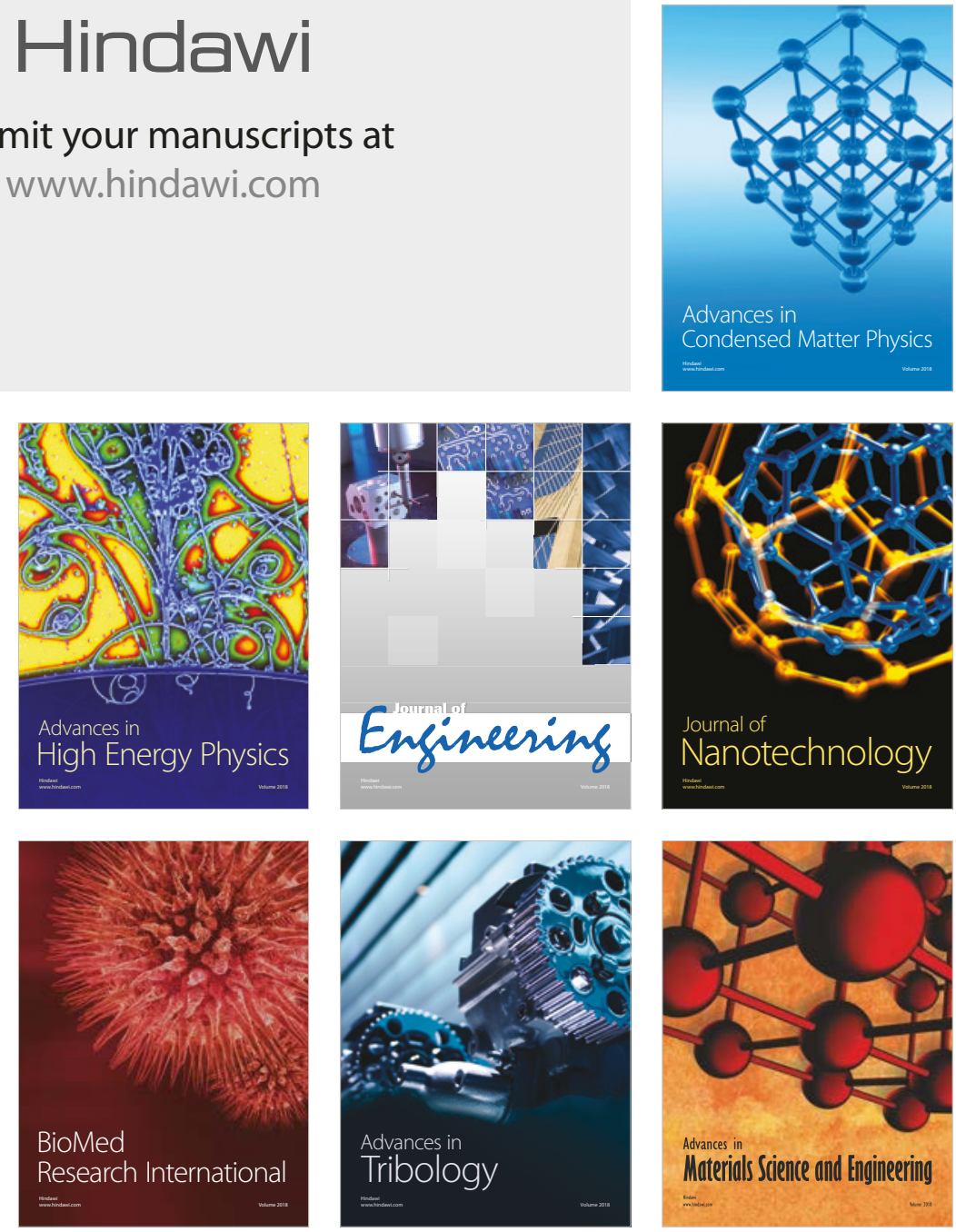